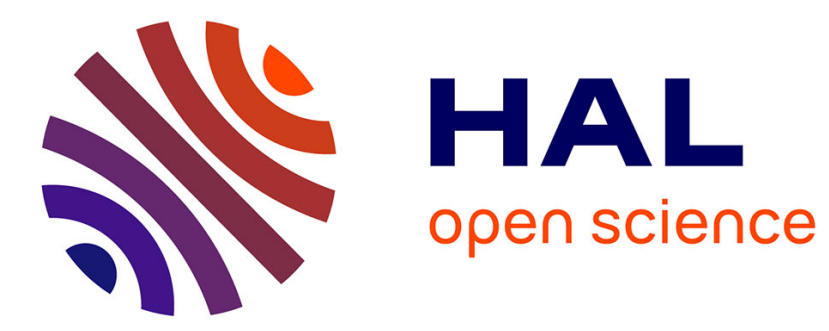

\title{
Fetal and postnatal development of the cortex: MRI and genetics
}

Jessica Dubois, Ghislaine Dehaene-Lambertz

\section{To cite this version:}

Jessica Dubois, Ghislaine Dehaene-Lambertz. Fetal and postnatal development of the cortex: MRI and genetics. Brain Mapping: An Encyclopedic Reference, 2, pp.11-19, 2015. hal-02436275

\section{HAL Id: hal-02436275 \\ https://hal.science/hal-02436275}

Submitted on 12 Jan 2020

HAL is a multi-disciplinary open access archive for the deposit and dissemination of scientific research documents, whether they are published or not. The documents may come from teaching and research institutions in France or abroad, or from public or private research centers.
L'archive ouverte pluridisciplinaire HAL, est destinée au dépôt et à la diffusion de documents scientifiques de niveau recherche, publiés ou non, émanant des établissements d'enseignement et de recherche français ou étrangers, des laboratoires publics ou privés. 


\title{
Fetal and postnatal development of the cortex: MRI and genetics
}

\author{
Jessica Dubois and Ghislaine Dehaene-Lambertz
}

\author{
Affiliations: \\ INSERM, U992, Cognitive Neuroimaging Unit \\ CEA/SAC/DSV/I2BM/NeuroSpin Center, Bât 145, point courrier 156 \\ 91191 Gif-sur-Yvette, France \\ Corresponding author: \\ Jessica Dubois, $\mathrm{PhD}$ \\ CEA/SAC/DSV/I2BM/NeuroSpin/Cognitive Neuroimaging Unit U992 \\ Bât 145, point courrier 156 \\ 91191 Gif-sur-Yvette, France \\ Email: jessica.dubois@centraliens.net
}

Brain Mapping: An Encyclopedic Reference, 2015. vol. 2, pp. 11-19. In: Arthur W. Toga, editor. Academic Press: Elsevier.

\section{Synopsis}

In the human brain, development of the cortex involves several overlapping mechanisms that proceed at different times and speeds among brain regions, from the first weeks of pregnancy until the end of adolescence. In the recent years, studies of healthy fetuses, infants and children using magnetic resonance imaging (MRI) have provided original insights on this complex process, notably on cortical folding and maturation. These studies have further detailed how cortical development may be impacted by genetic, epigenetic and environmental factors, but the precise relationships between MRI markers and infant cognitive development is still under evaluation.

\section{Keywords}

Cortex, Development, Folding, Genetic influences, Gyri and sulci, Inter-hemispheric asymmetries, Intra-uterine environment, Maturation, Microstructure, Myelination, Premature birth, Sexual dimorphism, Structural MRI, Thickness, Twin

\section{Glossary}

Folding of the cortex: process including the formation of cortical sulci and gyri during brain development.

Primary, secondary and tertiary folds: cortical folds that appear from $20 \mathrm{w}$ GA, from $32 \mathrm{w}$ GA, and around term age ( 40w GA) respectively.

\section{Nomenclature}

DTI: diffusion tensor imaging

GA: gestational age

MRI: magnetic resonance imaging

PTA: post-term age

STS: superior temporal sulcus

T1w / T2w images: T1- / T2-weighted images

w GA: weeks of gestational age 


\section{Introduction}

In the human brain, development of the cortex is a complex and long-lasting process that begins during the first weeks of pregnancy and lasts until the end of adolescence. It involves several overlapping mechanisms that proceed at different times and speeds among cortical regions (e.g. sensory regions develop early on and quickly, whereas associative regions, like frontal ones, develop later on and slowly). Since understanding normal development is essential before to consider the complexity of pathological conditions, this chapter focuses on studies using magnetic resonance imaging (MRI) in healthy fetuses, newborns, infants and children. In most of these studies, the main goal is to uncover in the human brain in vivo the well-known developmental processes described in the immature animal brain, despite challenges to test young children and especially infants (Dubois, et al. in press). Although the relationship between MRI structural markers and infant cognitive development is still unclear, these studies provide a first description of human cerebral maturation, useful for clinics. We here mainly review studies on the structural development of cortex, assessed by T1- and T2-weighted (T1w, T2w) images (chapter \#1) and diffusion tensor imaging (DTI) (chapter \#291). We successively detail 1) how the cortex grows and gets convoluted, 2) the microstructural maturation of the gray matter, 3) the inter-hemispherical asymmetries in cortical development, and 4) how this development might be impacted by genetic, epigenetic and environmental factors.

\section{The cortex development: structure and morphology}

The last weeks of pregnancy and the first postnatal months are marked by an intense increase in cortical volume and surface area, which progressively slows down after 2 years of age until adolescence.

\section{The early cerebral organization}

Due to the differences in cellularity, membrane density and water content of the different tissue compartments that affect contrasts and diffusion parameters, the last waves of neuronal migration are clearly visible with $\mathrm{T} 1 \mathrm{w}$ and T2w MRI in fetuses as young as 20 weeks of gestational age (wGA) (Girard, et al. 1995; Scott, et al. 2011) and with DTI in preterm newborns (Maas, et al. 2004) (Figure 1). Successive layers are described from the center of the brain to its surface: the germinal matrix from where neuroblasts migrate in the subventricular and periventricular zones; the intermediate zone which gathers radial glia and the developing axonal fibers of the future white matter; the subplate zone where migrating neurons are waiting until reaching their final location in the cortical plate (see chapter \#193), and finally the thin cortical plate. Between 20w and 26w GA, the subplate is seen as a hyperintense layer whose volume increases, first globally in proportion with the supratentorial volume, and secondly at different rates among brain regions (Corbett-Detig, et al. 2011). It becomes progressively isointense, and thus difficult to identify from $35 \mathrm{wGA}$ on, although it might still be present until the end of the first year, notably in frontal regions (Kostovic, et al. 2014).

\section{Cortical growth}

Because contrasts in T1w and T2w images evolve with maturation (Dubois, et al. in press), the comparison of cortical volume across ages (Figure 2a) should remain cautious. In utero, the volume of the cortical plate increases from around $10 \mathrm{~mL}$ at $21 \mathrm{wGA}$ to $70 \mathrm{~mL}$ at $31 \mathrm{wGA}$ (Scott, et al. 2011), and developmental rates differ among brain regions, with higher volume increases in parietal and occipital regions than in frontal lobe (Rajagopalan, et al. 2011). In preterm newborns, the volume increases from around $25 \mathrm{~mL}$ at $29 \mathrm{w}$ GA to $250 \mathrm{~mL}$ at $48 \mathrm{w}$ GA (Kuklisova-Murgasova, et al. 2011). During the first two years after term birth, brain growth is mainly due to gray matter development (Gilmore, et al. 2007);(Knickmeyer, et al. 2008) contrarily to the following years (Matsuzawa, et al. 2001). The cortical volume increases much 
more during the first postnatal year (by around 106\%), than during the second year (by 18\%), and faster in association cortices, particularly in the frontal and parietal lobes, relatively to the primary motor and sensory cortices (Gilmore, et al. 2012) (Figure 3a).

The pre-adolescent increase in cortical volume is followed by a post-adolescent decrease, with different growth peaks across brain regions, varying from around 10 years (female parietal lobe) to 17 years (female temporal lobe) (Giedd, et al. 1999) (Figure 2a). Higher-order association cortices mature after lower-order somatosensory and visual cortices, and phylogenetically older regions mature earlier than newer regions (Gogtay, et al. 2004).

\section{Cortical folding}

Concurrently with brain growth, the cortex is getting folded during the last trimester of pregnancy. Dedicated tools and morphometric analyses have enabled to map in detail the developing cortical surface and growth patterns in fetuses as young as $20 \mathrm{w}$ GA (Habas, et al. 2012) and in preterm newborns imaged shortly after birth (Dubois, et al. 2008b) (Figure 1c). These in vivo studies confirm earlier post-mortem observations (Chi, et al. 1977a) and show a precise calendar (with the appearance of primary folds around 20w GA, secondary folds around $32 \mathrm{w}$ GA and tertiary folds around term), that can be used as a robust marker of brain maturation. Gyrification becomes manifest after 24w GA (Rajagopalan, et al. 2011), and greatly heightens during the last weeks before term (Figure 2b) (Angleys, et al. 2014; Dubois, et al. 2008b). Although some variability is observed among individuals, the regional pattern is consistent over the brain surface: sulcation starts in the central region and proceeds first towards the parietal, temporal and occipital lobes, second towards the frontal lobe (Dubois, et al. 2008b; Ruoss, et al. 2001).

At term, the cortical surface area is three times smaller than in adults, but the cortex is roughly similarly folded, and the most variable regions among individuals are the same across newborns and adults (Hill, et al. 2010a). Noticing the non-uniform pattern of cortical growth among brain regions, Hill and colleagues proposed that it resembles the pattern of evolutionary expansion between human and macaque monkey, with phylogenetically recent regions being the least developed at birth (Hill, et al. 2010b).

\section{Modeling cortical development}

Why does the human brain fold? The cortical structure appears as a closed surface, with fundamental mechanical properties of elasticity and plasticity (Toro and Burnod 2005). Glial and axonal fibers might apply tension radially to this surface while it grows and consequently folds (Van Essen 1997). According to genetic control or mechanistic constraints, the folding may organize around stable points, also called sulcal "roots" (Regis, et al. 2005) or "pits" (Lohmann, et al. 2008) in the adult brain. So far, this hypothesis has been confirmed in preterm newborns, in whom stable inter-individual pits have been revealed along the central and superior temporal sulci using analyses of the surface curvature and depth (Operto, et al. 2012), and also in infants, in whom displacement fields analyses have detected "growth seeds" on longitudinal data (Lefèvre, et al. 2009).

\section{The maturation of cortical microstructure}

These macro-structural changes are the visible marker of the microstructural evolution, marked by synaptic outburst and pruning, modifications in dendritic branching and fiber myelination.

\section{Changes in cortical microstructure during the preterm period}

In the developing brain of preterm newborns, DTI provides valuable information on cortical architecture and is sensitive to the regional heterogeneity in cortical development. The 
diffusion of water molecules is anisotropic in the cortical plate around 26w GA presenting a radial orientation of the tensor main direction, then becomes isotropic from around 36w GA (Dudink, et al. 2010; McKinstry, et al. 2002) (Figure 1b). This change is explained by the early radial deployment of glial fibers and apical dendrites of pyramidal neurons, followed by the elongation and complex branching of neuronal connections (basal dendrites for the pyramidal neurons and thalamo-cortical afferents). Besides, mean diffusivity increases between $26 \mathrm{w}$ and 32w GA, and decreases thereafter, suggesting competing mechanisms (McKinstry, et al. 2002): decrease in cell density associated with programmed cell death, addition of neuropils between the neuronal somas, versus decreasing water content. These changes are not uniform over the brain (Ball, et al. 2013; Deipolyi, et al. 2005), and they are not linear at least for some regions, such as the right superior temporal sulcus (STS) and lateral occipito-temporal gyrus (Aeby, et al. 2012).

\section{Cortical maturation during infancy}

Accompanying the complex evolution of cortical microstructure, the dendritic and axonal fibers get myelinated. It is now possible to quantify this maturation in vivo by taking advantages of the changes in $\mathrm{T} 1$ and $\mathrm{T} 2$ signals induced by modifications in water and iron contents. For example, using normalized T2w images in infants, Leroy and colleagues recovered the regional asynchrony of maturation between primary and associative regions, as first described in postmortem studies (Figure 3b), and further uncovered a gradient of maturation within the linguistic network, the STS appearing less mature than the inferior frontal region (Leroy, et al. 2011a). Travis and colleagues also measured significant age effects within bilateral inferior lateral and anterovental temporal regions, dorsomedial frontal, and superior parietal cortices during the second postnatal year (Travis, et al. 2013). T1w signal intensity and T1w/T2w myelin mapping reveal that cortical maturation is ongoing until 30 years of age in some brain regions, and that occipital visual cortices display the earliest maturation while superior frontal regions have the most protracted maturation (Grydeland, et al. 2013; Westlye, et al. 2010). Besides, the magnetic susceptibility displays an exponential growth, suggesting a continuous increase in iron content (Li, et al. 2013b).

\section{Changes in cortical thickness during childhood and adolescence}

In newborns, average cortical thickness is around $1.3 \mathrm{~mm}$ between 27 and $45 \mathrm{w}$ GA (Xue, et al. 2007). It further increases with age, ranging from $1.5 \mathrm{~mm}$ in occipital regions to $5.5 \mathrm{~mm}$ in dorsomedial frontal cortex during childhood (Sowell, et al. 2004). As for cortical volume, this increase is followed during adolescence by an asynchronous decrease across brain regions (Shaw, et al. 2007; Shaw, et al. 2008; Sowell, et al. 2004). These thickness changes are correlated across regions linked with rich structural and functional connectivity (e.g. frontotemporal association regions) (Raznahan, et al. 2011a).

It has been argued that cortical thinning would be an artefactual observation resulting from myelination that would blur the segmentation of the gray/white matter boundary on MR images. However, age-related evolutions of thickness and maturation are distinct over the life span (Westlye, et al. 2010), and developmental patterns of superficial white matter diverge from the widespread changes in thickness (Wu, et al. 2013). Relationships between cortical thickness, volume, surface area and folding are also a matter of debate. Between 7 and 23 years of age, the regional patterns and timings of developmental trajectories differ for thickness and surface area, suggesting that these parameters rely on different mechanisms (Wierenga, et al. 2013). Nevertheless, thinning seems associated with sulcal widening and gyral white matter expansion during adolescence, period when the cortex flattens (Aleman-Gomez, et al. 2013). Non-linear changes in cortical volume emerge from the complex age-dependent interactions of changes in thickness and surface area, also relying on gyrification (Raznahan, et al. 2011b). 


\section{Inter-hemispheric asymmetries in cortical development}

The two cerebral hemispheres do not develop symmetrically during the fetal and postnatal life, suggesting early structural bases of functional lateralization. Post-mortem studies have described that the right hemisphere shows gyral complexity earlier than the left, while Heschl's gyrus and planum temporale are more developed on the left side by $31 \mathrm{w} \mathrm{GA} \mathrm{(Chi,} \mathrm{et} \mathrm{al.} \mathrm{1977a;}$ Chi, et al. 1977b). In vivo studies have confirmed these cortical asymmetries (Figure 4). STS folds earlier on the right side than on the left side in in utero fetuses (Habas, et al. 2012; Kasprian, et al. 2011) and in preterm newborns (Dubois, et al. 2008b), and the right STS remains deeper than the left in newborns at term (Hill, et al. 2010a), infants (Glasel, et al. 2011; Li, et al. 2013a), children and adults (Leroy, et al. in preparation), in association with an advanced maturation during infancy (Leroy, et al. 2011a).

The leftward elongation of planum temporale and thickening of Heschl's gyrus are also detected early on (Dubois, et al. 2010; Glasel, et al. 2011; Hill, et al. 2010a; Li, et al. 2013a). The posterior end of the Sylvian fissure is shifted forward and upward in the right hemisphere of infants (Glasel, et al. 2011; Li, et al. 2013a), and this asymmetry increases with age (Sowell, et al. 2002). Furthermore, the anterior region of the sylvian fissure seems to grow earlier on the left side (Dubois, et al. 2010; Li, et al. 2013a), close to Broca's region which matures before than its right counterpart (Leroy, et al. 2011a). These maturational asymmetries in posterior STS and Broca's region are finally associated with asymmetries in the arcuate fasciculus connecting these cortical areas (Dubois, et al. 2009; Leroy, et al. 2011a).

Thus perisylvian regions involved in language processing in the left hemisphere and in social contact in the right hemisphere follow a different developmental calendar. The relation between structural and functional lateralization is still not clear (Dehaene-Lambertz, et al. 2006) but early asymmetric expression of several genes, like LMO4 which is consistently more expressed in right superior temporal regions than in left regions of human embryos (Sun, et al. 2005), suggest an evolutionary pressure on these regions.

\section{Influence of genetic, epigenetic and environmental factors}

Several studies have related differences in cognitive performances with variations in cortical development during childhood and adolescence (Lu, et al. 2007; Shaw, et al. 2006). Nevertheless the variability of detailed relationships among studies suggests that numerous factors affecting cognitive performances and brain development (e.g. socio-economic status, education, birth-weight, nutrition, stress) should be taken into account. Furthermore, since age is the main variable driving brain changes, longitudinal studies should be preferred to isolate the crucial factors and their impact on precise structures along the developmental trajectory (Raznahan, et al. 2011b). Too numerous pathologies disrupt development, therefore we will only focus on normal development, except for prematurity, a major societal issue.

\section{Sexual dimorphism}

Whereas no difference in folding is detected among fetuses of the same age (Chi, et al. 1977a), males already have larger cortical volumes than females after preterm (Dubois, et al. 2008b) or term birth (Gilmore, et al. 2007). During childhood and adolescence, this dimorphism strengthens, with volumes being 10\% larger in boys (Giedd, et al. 1999) correlating with body mass index (BrainDevelopmentCooperativeGroup 2012). The age-related changes in volume peak slightly earlier ( 1 to 2 years) in girls, but the curve shape does not differ among genders (Giedd, et al. 1999; Lenroot, et al. 2007).

Girls tend to have larger grey matter volume relative to brain size than boys (Groeschel, et al. 2010) and gender differences are more pronounced for volume and surface area than for cortical thickness (Wierenga, et al. 2013), for which sex differences are region-specific (Sowell, 
et al. 2007). During adolescence, the pattern of differences in cortical thickness between genders accelerates, notably a wave of maturation sweeps frontal sub-regions with a delay in males compared with females (Raznahan, et al. 2010) probably related to the earlier female puberty. The acceleration of cortical thickness changes during this period is different across regions and is modulated by the level of cerebral androgen receptor signaling in both males and females (Raznahan, et al. 2010). The effect of gender is strikingly different in the superior frontal region (accelerated loss in males relatively to females) and the parietal lobule (reverse pattern), suggesting possible relationship with gender cognitive differences (e.g. better social cognition in females vs better visuo-spatial cognition in males) (Raznahan, et al. 2010) despite no direct correlation was established.

Beside hormonal influence, sex chromosome gene expression also directly influences gray matter volume in different brain regions (parieto-occipital, temporo-insular), as demonstrated during the early stages of puberty in normal children and children with Turner syndrome (females missing one X-chromosome) and Klinefelter syndrome (males having an additional X-chromosome) (Hong, et al. 2014). These developmental studies demonstrate the robust influence of hormones and sex chromosome gene dosages on cortical development (see chapter \#196), and underscore the need to precisely match gender and age when evaluating normal or pathological brain functioning.

\section{Genetic influences}

To assess how genetics vs. environment influence cortical development, most MRI studies have relied on the longitudinal follow-up of pediatric monozygotic and dizygotic twins. Cortical volume and depth are highly correlated within monozygotic twin pairs but surface measures are more prone to environmental influences (White, et al. 2002). The volume heritability decreases with age (Wallace, et al. 2006), differently among brain regions (Giedd, et al. 2007). Cortical density is increasingly similar in subjects with increasing genetic affinity, particularly in frontal, sensorimotor and perisylvian language regions (Thompson, et al. 2001). The degree of genetic influence on cortical thickness also differs among brain regions (van Soelen, et al. 2012): regions that develop earlier show greater genetic effects during early childhood, while later developing regions are more heritable in adolescents than children (Lenroot, et al. 2009).

So far, the heritability in cortical patterning has not been studied during development, but in adults the similarity in sulcal graphs is higher in twin pairs than in unrelated pairs, suggesting a genetic influence on cortical folding (Im, et al. 2011). Finally, genetics also influences interhemispheric asymmetries: asymmetries in planum temporale and Sylvian fissure are slightly heritable during childhood. However heritability decreases when twins with discordant writing hand or large birth weight differences are included (Eckert, et al. 2002), suggesting that prenatal and postnatal factors should not be neglected.

\section{Intrauterine environment and gestational duration}

In agreement with post-mortem studies (Chi, et al. 1977a), an in vivo study of preterm newborns has shown a delayed but harmonious maturation in twins at birth in comparison with singletons (Dubois, et al. 2008a), whereas the gyrification of newborns with intrauterine growth restriction is discordant to the normal developmental trajectory. Within monozygotic pairs in a normal birth-weight range, higher birth weight is associated with higher intelligence quotient in adolescence, and with higher cortical volume and surface area notably in several perisylvian regions (Raznahan, et al. 2012). This relation is not observed in singletons, and is weaker in dizygotic twins. These results highlight that a slightly more difficult prenatal environment interacting with genetic expression has a durable effect (although weak: 2 points of IQ in the above study). 
Premature birth also strongly modifies subsequent brain growth, even in the absence of major destructive brain lesions. In comparison with normal newborns, preterm newborns at term equivalent age show alterations in cortical volume (reductions in most brain regions except increases in occipital regions) (Padilla, et al. 2014), folding (Melbourne, et al. 2014) and maturation (Ball, et al. 2013), in a dose-dependent fashion related to the premature exposure to extra-uterine environment (development increases with gestational age at birth). From 23 to 48w GA, the scaling exponent relating surface area and volume decreases with increasing prematurity (Kapellou, et al. 2006).

Prematurity consequences further stretch to infancy and childhood, with early brain measures predicting future cognitive development. Cortical folding in preterms at birth correlates with cortical volume and neurobehavioral development at term equivalent age (Dubois, et al. 2008a). Language abilities of 2-year-old infants born preterm are negatively correlated with DTI diffusivities measured in left superior temporal gyrus at term equivalent age, suggesting that the early stage of development of this region is crucial for later language acquisition (Aeby, et al. 2013). The rate of microstructural maturation assessed between 27 and 46w GA predicts neurodevelopmental scores at 2 years of age (Ball, et al. 2013). At 8 years of age, children born preterm demonstrate increased bilateral temporal lobe gyrification compared to term controls, and the left increase is negatively correlated with reading recognition scores (Kesler, et al. 2006). Even in children born full term, a longer duration of gestation (until 41w GA) seems beneficial, being associated with region-specific increases in cortical density (Davis, et al. 2011). These studies outline that cognitive functions have their roots in early development but questions remain on the causal disturbing mechanisms, notably on the respective roles of microscopic brain lesions, of exposure to the too stimulating outside world vs to the maternal protective and filtering environment.

\section{Conclusion}

MRI now enables to map and characterize the dynamics of cortical development, as well as the development of structural and functional connectivity (see chapter \#360), highlighting the structural bases of cognitive development. These studies are challenging in healthy infants and require dedicated methodologies for image acquisition and post-processing (Dubois, et al. in press), but it's worth the effort since markers of maturation are required to better understand pathological mechanisms or the deleterious effects of early disturbances such as prematurity. However, if clear effects of age, genes, hormonal status or nutrition are observed on structural images, the causal relationships between these observations and cognition are still unknown due to the complex interactions between these factors and the delicacy of the neural circuitry still non captured by MR images.

\section{Acknowledgment}

The authors thank P.S. Hüppi for images of preterm newborns (Figure 1) and F. Leroy for images of cortical maturation (Figure 3). The finalization of this work received support from the European Union Seventh Framework Program (FP7/2007-2013, grant agreement $\mathrm{n}^{\circ}$ 604102), the French National Agency for Research, the Fyssen Foundation, the Fondation de France, the Ecole des Neurosciences de Paris, the Fondation Motrice and the McDonnell Foundation. 
Figure 1: Structural imaging of the developing brain.

T2w images (a), DTI-RGB directionality maps (b) and inner cortical surfaces (c: (Dubois, et al. 2008b; Leroy, et al. 2011b)) are presented for 3 preterm newborns of different ages and an infant aged $4 \mathrm{w}$ old (PTA: post-term age). Note that anisotropy decreases with age in the preterm cortex (b).

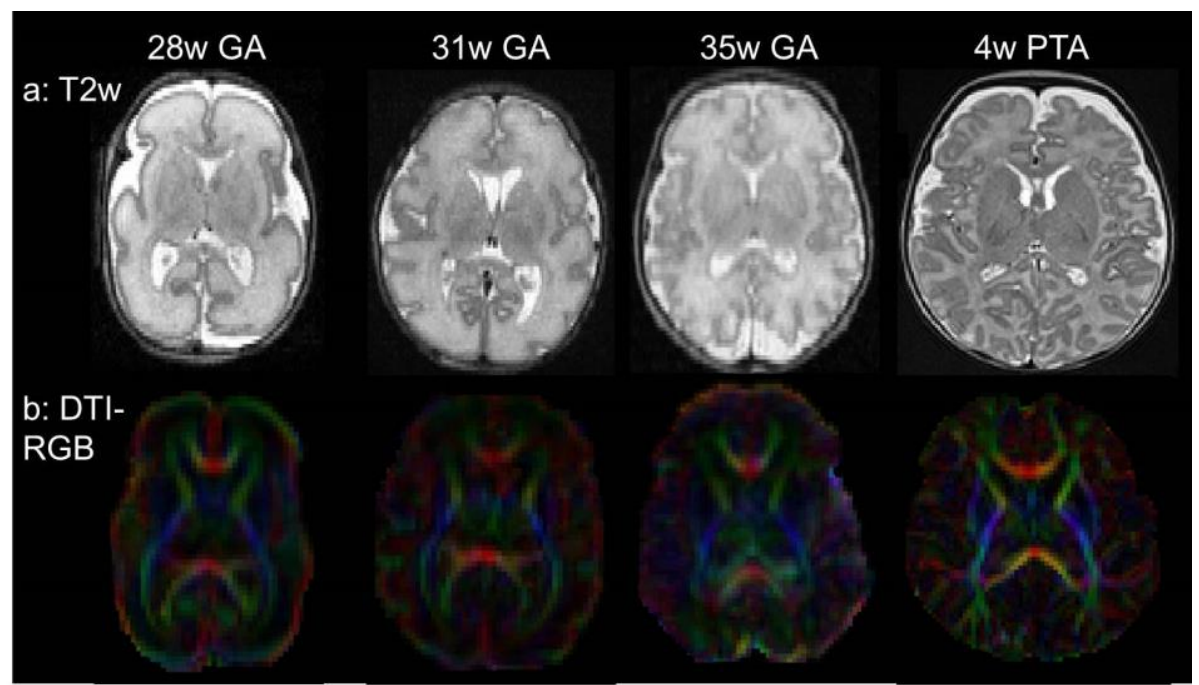

c: Inner cortical surface

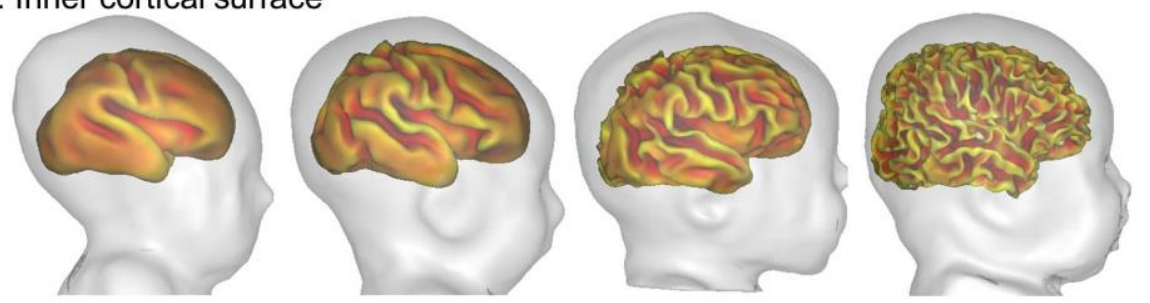


Figure 2: Changes in cortical volume, surface area and folding during development.

Cortical volume (a) increases during the preterm period (Kuklisova-Murgasova, et al. 2011), infancy (Knickmeyer, et al. 2008) and childhood, before decreasing during adolescence (Giedd, et al. 1999). The increases in surface area and sulcation (b) are major during the last gestational weeks, going with the growth in brain size (Angleys, et al. 2014).

a. Changes in the volume of cortex during childhood
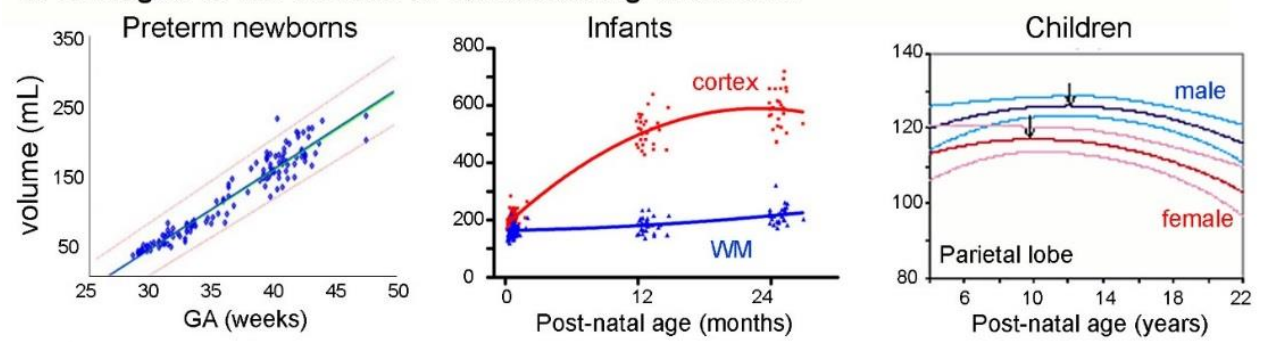

b. Development of the cortical surface in newborns Inner cortical surface
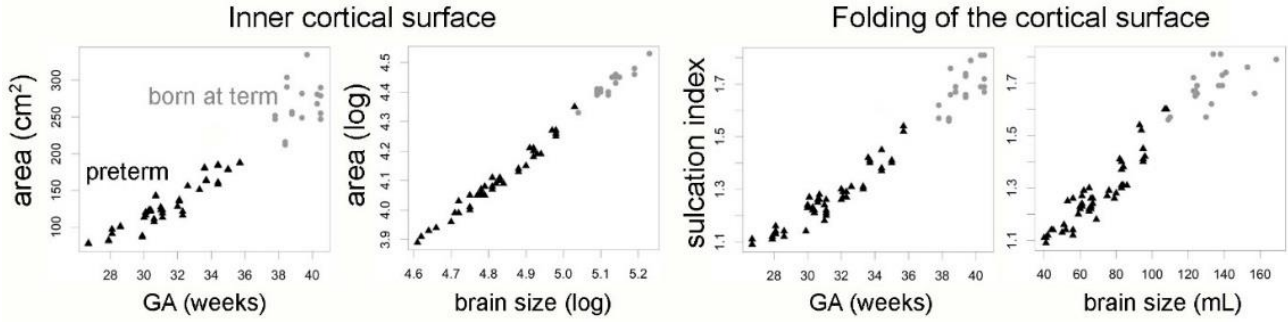
Figure 3: Asynchronous development of brain regions

During the first post-natal year, cortical regions demonstrate different rates of volume increase (a) (Gilmore, et al. 2012) and maturation (b) (Leroy, et al. 2011a) : primary sensory-motor regions grow less and appear more mature (red arrows on T2w images) than associative regions.

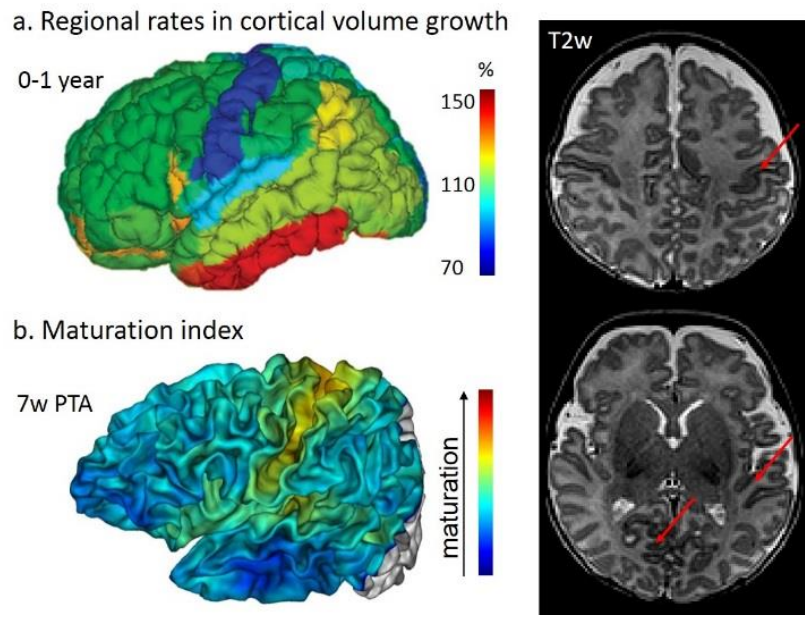


Figure 4: Inter-hemispheric asymmetries in cortical development

The cortex folds asymmetrically in peri-sylvian regions (a), as shown in preterm newborns (Dubois, et al. 2010) and infants (Li, et al. 2013a). Notably the STS (b) is deeper (Glasel, et al. 2011) and more mature (Leroy, et al. 2011a) on the right side than on the left.

a. Whole-brain analyses of inter-hemispheric asymmetries
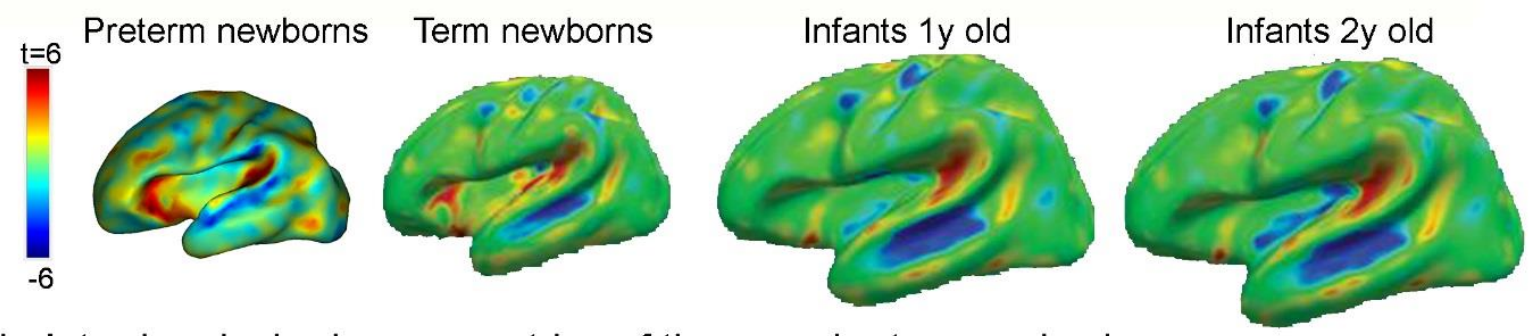

b. Inter-hemispheric asymmetries of the superior temporal sulcus

STS depth STS maturation

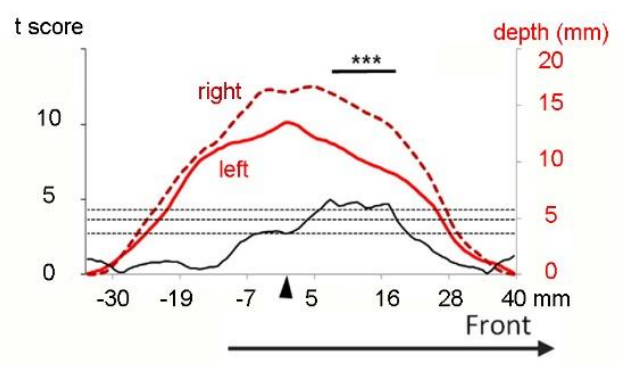

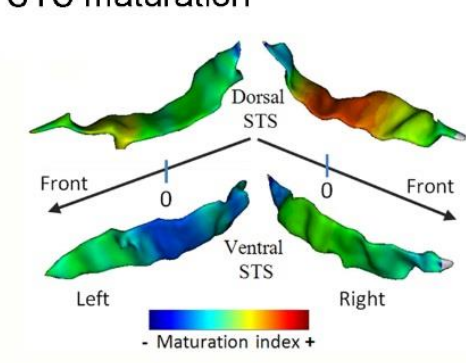

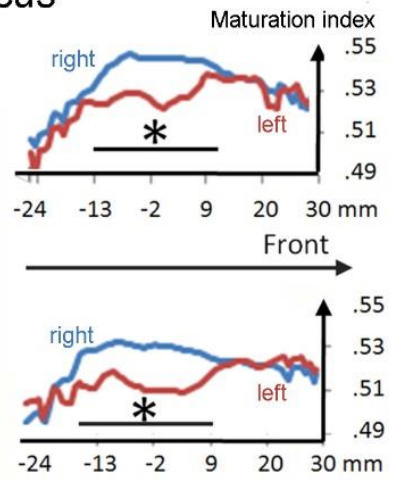




\section{References}

Aeby A, De Tiege X, Creuzil M, David P, Baleriaux D, Van Overmeire B, Metens T, Van Bogaert P. 2013. Language development at 2 years is correlated to brain microstructure in the left superior temporal gyrus at term equivalent age: A diffusion tensor imaging study. Neuroimage 78(C):145-151.

Aeby A, Van Bogaert P, David P, Baleriaux D, Vermeylen D, Metens T, De Tiege X. 2012. Nonlinear microstructural changes in the right superior temporal sulcus and lateral occipitotemporal gyrus between 35 and 43weeks in the preterm brain. Neuroimage 63(1):104-110.

Aleman-Gomez Y, Janssen J, Schnack H, Balaban E, Pina-Camacho L, Alfaro-Almagro F, Castro-Fornieles J, Otero S, Baeza I, Moreno D and others. 2013. The Human Cerebral Cortex Flattens during Adolescence. J Neurosci 33(38):15004-15010.

Angleys H, Germanaud D, Leroy F, Hertz-Pannier L, Mangin JF, Lazeyras F, Hüppi PS, Lefèvre J, Dubois J. 2014. Successive waves of cortical folding in the developing brain using spectral analysis of gyrification. Proceedings of OHBM.

Ball G, Srinivasan L, Aljabar P, Counsell SJ, Durighel G, Hajnal JV, Rutherford MA, Edwards AD. 2013. Development of cortical microstructure in the preterm human brain. Proc Natl Acad Sci U S A 110(23):9541-9546.

BrainDevelopmentCooperativeGroup. 2012. Total and regional brain volumes in a population-based normative sample from 4 to 18 years: the NIH MRI Study of Normal Brain Development. Cereb Cortex 22(1):1-12.

Chi JG, Dooling EC, Gilles FH. 1977a. Gyral development of the human brain. Ann Neurol 1(1):86-93.

Chi JG, Dooling EC, Gilles FH. 1977b. Left-right asymmetries of the temporal speech areas of the human fetus. Arch Neurol 34(6):346-8.

Corbett-Detig J, Habas PA, Scott JA, Kim K, Rajagopalan V, McQuillen PS, Barkovich AJ, Glenn OA, Studholme C. 2011.3D global and regional patterns of human fetal subplate growth determined in utero. Brain Struct Funct 215(3-4):255-63.

Davis EP, Buss C, Muftuler LT, Head K, Hasso A, Wing DA, Hobel C, Sandman CA. 2011. Children's Brain Development Benefits from Longer Gestation. Front Psychol 2:1.

Dehaene-Lambertz G, Hertz-Pannier L, Dubois J. 2006. Nature and nurture in language acquisition: anatomical and functional brain-imaging studies in infants. Trends Neurosci 29(7):367-73.

Deipolyi AR, Mukherjee P, Gill K, Henry RG, Partridge SC, Veeraraghavan S, Jin H, Lu Y, Miller SP, Ferriero DM and others. 2005. Comparing microstructural and macrostructural development of the cerebral cortex in premature newborns: diffusion tensor imaging versus cortical gyration. Neuroimage 27(3):579-86.

Dubois J, Benders M, Borradori-Tolsa C, Cachia A, Lazeyras F, Ha-Vinh Leuchter R, Sizonenko SV, Warfield SK, Mangin JF, Huppi PS. 2008a. Primary cortical folding in the human newborn: an early marker of later functional development. Brain 131(Pt 8):2028-41.

Dubois J, Benders M, Cachia A, Lazeyras F, Ha-Vinh Leuchter R, Sizonenko SV, Borradori-Tolsa C, Mangin JF, Huppi PS. 2008b. Mapping the early cortical folding process in the preterm newborn brain. Cereb Cortex 18(6):1444-54.

Dubois J, Benders M, Lazeyras F, Borradori-Tolsa C, Leuchter RH, Mangin JF, Huppi PS. 2010. Structural asymmetries of perisylvian regions in the preterm newborn. Neuroimage 52(1):32-42.

Dubois J, Dehaene-Lambertz G, Kulikova S, Poupon C, Hüppi PS, Hertz-Pannier L. in press. The early development of brain white matter: a review of imaging studies in fetuses, newborns and infants. Neuroscience DOI 10.1016/j.neuroscience.2013.12.044.

Dubois J, Hertz-Pannier L, Cachia A, Mangin JF, Le Bihan D, Dehaene-Lambertz G. 2009. Structural asymmetries in the infant language and sensori-motor networks. Cereb Cortex 19(2):414-23.

Dudink J, Buijs J, Govaert P, van Zwol AL, Conneman N, van Goudoever JB, Lequin M. 2010. Diffusion tensor imaging of the cortical plate and subplate in very-low-birth-weight infants. Pediatr Radiol 40(8):1397404.

Eckert MA, Leonard CM, Molloy EA, Blumenthal J, Zijdenbos A, Giedd JN. 2002. The epigenesis of planum temporale asymmetry in twins. Cereb Cortex 12(7):749-55.

Giedd JN, Blumenthal J, Jeffries NO, Castellanos FX, Liu H, Zijdenbos A, Paus T, Evans AC, Rapoport JL. 1999. Brain development during childhood and adolescence: a longitudinal MRI study. Nat Neurosci 2(10):8613.

Giedd JN, Schmitt JE, Neale MC. 2007. Structural brain magnetic resonance imaging of pediatric twins. Hum Brain Mapp 28(6):474-81.

Gilmore JH, Lin W, Prastawa MW, Looney CB, Vetsa YS, Knickmeyer RC, Evans DD, Smith JK, Hamer RM, Lieberman JA and others. 2007. Regional gray matter growth, sexual dimorphism, and cerebral asymmetry in the neonatal brain. J Neurosci 27(6):1255-60.

Gilmore JH, Shi F, Woolson SL, Knickmeyer RC, Short SJ, Lin W, Zhu H, Hamer RM, Styner M, Shen D. 2012. Longitudinal Development of Cortical and Subcortical Gray Matter from Birth to 2 Years. Cereb Cortex. 
Girard N, Raybaud C, Poncet M. 1995. In vivo MR study of brain maturation in normal fetuses. AJNR Am J Neuroradiol 16(2):407-13.

Glasel H, Leroy F, Dubois J, Hertz-Pannier L, Mangin JF, Dehaene-Lambertz G. 2011. A robust cerebral asymmetry in the infant brain: The rightward superior temporal sulcus. Neuroimage 58(3):716-23.

Gogtay N, Giedd JN, Lusk L, Hayashi KM, Greenstein D, Vaituzis AC, Nugent TF, 3rd, Herman DH, Clasen LS, Toga AW and others. 2004. Dynamic mapping of human cortical development during childhood through early adulthood. Proc Natl Acad Sci U S A 101(21):8174-9.

Groeschel S, Vollmer B, King MD, Connelly A. 2010. Developmental changes in cerebral grey and white matter volume from infancy to adulthood. Int J Dev Neurosci 28(6):481-9.

Grydeland H, Walhovd KB, Tamnes CK, Westlye LT, Fjell AM. 2013. Intracortical Myelin Links with Performance Variability across the Human Lifespan: Results from T1- and T2-Weighted MRI Myelin Mapping and Diffusion Tensor Imaging. J Neurosci 33(47):18618-30.

Habas PA, Scott JA, Roosta A, Rajagopalan V, Kim K, Rousseau F, Barkovich AJ, Glenn OA, Studholme C. 2012. Early folding patterns and asymmetries of the normal human brain detected from in utero MRI. Cereb Cortex 22(1):13-25.

Hill J, Dierker D, Neil J, Inder T, Knutsen A, Harwell J, Coalson T, Van Essen D. 2010a. A surface-based analysis of hemispheric asymmetries and folding of cerebral cortex in term-born human infants. J Neurosci 30(6):2268-76

Hill J, Inder T, Neil J, Dierker D, Harwell J, Van Essen D. 2010b. Similar patterns of cortical expansion during human development and evolution. Proc Natl Acad Sci U S A 107(29):13135-40.

Hong DS, Hoeft F, Marzelli MJ, Lepage JF, Roeltgen D, Ross J, Reiss AL. 2014. Influence of the X-chromosome on neuroanatomy: evidence from turner and klinefelter syndromes. J Neurosci 34(10):3509-16.

Im K, Pienaar R, Lee JM, Seong JK, Choi YY, Lee KH, Grant PE. 2011. Quantitative comparison and analysis of sulcal patterns using sulcal graph matching: a twin study. Neuroimage 57(3):1077-86.

Kapellou O, Counsell SJ, Kennea N, Dyet L, Saeed N, Stark J, Maalouf E, Duggan P, Ajayi-Obe M, Hajnal J and others. 2006. Abnormal cortical development after premature birth shown by altered allometric scaling of brain growth. PLoS Med 3(8):e265.

Kasprian G, Langs G, Brugger PC, Bittner M, Weber M, Arantes M, Prayer D. 2011. The prenatal origin of hemispheric asymmetry: an in utero neuroimaging study. Cereb Cortex 21(5):1076-83.

Kesler SR, Vohr B, Schneider KC, Katz KH, Makuch RW, Reiss AL, Ment LR. 2006. Increased temporal lobe gyrification in preterm children. Neuropsychologia 44(3):445-53.

Knickmeyer RC, Gouttard S, Kang C, Evans D, Wilber K, Smith JK, Hamer RM, Lin W, Gerig G, Gilmore JH. 2008. A structural MRI study of human brain development from birth to 2 years. J Neurosci 28(47):12176-82.

Kostovic I, Jovanov-Milosevic N, Rados M, Sedmak G, Benjak V, Kostovic-Srzentic M, Vasung L, Culjat M, Huppi P, Judas M. 2014. Perinatal and early postnatal reorganization of the subplate and related cellular compartments in the human cerebral wall as revealed by histological and MRI approaches. Brain Struct Funct 219(1):231-53.

Kuklisova-Murgasova M, Aljabar P, Srinivasan L, Counsell SJ, Doria V, Serag A, Gousias IS, Boardman JP, Rutherford MA, Edwards AD and others. 2011. A dynamic 4D probabilistic atlas of the developing brain. Neuroimage 54(4):2750-63.

Lefèvre J, Leroy F, Khan S, Dubois J, Huppi PS, Baillet S, Mangin JF. 2009. Identification of growth seeds in the neonate brain through surfacic Helmholtz decomposition. Inf Process Med Imaging 21:252-63.

Lenroot RK, Gogtay N, Greenstein DK, Wells EM, Wallace GL, Clasen LS, Blumenthal JD, Lerch J, Zijdenbos AP, Evans AC and others. 2007. Sexual dimorphism of brain developmental trajectories during childhood and adolescence. Neuroimage 36(4):1065-73.

Lenroot RK, Schmitt JE, Ordaz SJ, Wallace GL, Neale MC, Lerch JP, Kendler KS, Evans AC, Giedd JN. 2009. Differences in genetic and environmental influences on the human cerebral cortex associated with development during childhood and adolescence. Hum Brain Mapp 30(1):163-74.

Leroy F, Cai Q, Bogart S, Dubois J, Coulon O, Monzalvo K, Glasel H, Van der Haegen L, Bénézit A, Lin CP and others. in preparation. A unique human brain landmark: The depth asymmetry of the superior temporal sulcus.

Leroy F, Glasel H, Dubois J, Hertz-Pannier L, Thirion B, Mangin JF, Dehaene-Lambertz G. 2011a. Early maturation of the linguistic dorsal pathway in human infants. J Neurosci 31(4):1500-6.

Leroy F, Mangin JF, Rousseau F, Glasel H, Hertz-Pannier L, Dubois J, Dehaene-Lambertz G. 2011b. Atlas-free surface reconstruction of the cortical grey-white interface in infants. PLoS One 6(11):e27128.

Li G, Nie J, Wang L, Shi F, Lyall AE, Lin W, Gilmore JH, Shen D. 2013a. Mapping Longitudinal Hemispheric Structural Asymmetries of the Human Cerebral Cortex From Birth to 2 Years of Age. Cereb Cortex. 
Li W, Wu B, Batrachenko A, Bancroft-Wu V, Morey RA, Shashi V, Langkammer C, De Bellis MD, Ropele S, Song AW and others. 2013b. Differential developmental trajectories of magnetic susceptibility in human brain gray and white matter over the lifespan. Hum Brain Mapp.

Lohmann G, von Cramon DY, Colchester AC. 2008. Deep sulcal landmarks provide an organizing framework for human cortical folding. Cereb Cortex 18(6):1415-20.

Lu L, Leonard C, Thompson P, Kan E, Jolley J, Welcome S, Toga A, Sowell E. 2007. Normal developmental changes in inferior frontal gray matter are associated with improvement in phonological processing: a longitudinal MRI analysis. Cereb Cortex 17(5):1092-9.

Maas LC, Mukherjee P, Carballido-Gamio J, Veeraraghavan S, Miller SP, Partridge SC, Henry RG, Barkovich AJ, Vigneron DB. 2004. Early laminar organization of the human cerebrum demonstrated with diffusion tensor imaging in extremely premature infants. Neuroimage 22(3):1134-40.

Matsuzawa J, Matsui M, Konishi T, Noguchi K, Gur RC, Bilker W, Miyawaki T. 2001. Age-related volumetric changes of brain gray and white matter in healthy infants and children. Cereb Cortex 11(4):335-42.

McKinstry RC, Mathur A, Miller JH, Ozcan A, Snyder AZ, Schefft GL, Almli CR, Shiran SI, Conturo TE, Neil JJ. 2002. Radial organization of developing preterm human cerebral cortex revealed by non-invasive water diffusion anisotropy MRI. Cereb Cortex 12(12):1237-43.

Melbourne A, Kendall GS, Cardoso MJ, Gunny R, Robertson NJ, Marlow N, Ourselin S. 2014. Preterm birth affects the developmental synergy between cortical folding and cortical connectivity observed on multimodal MRI. Neuroimage.

Operto G, Auzias G, Le Troter A, Perrot M, Rivière D, Dubois J, Hüppi PS, Coulon O, Mangin JF. 2012. Structural group analysis of cortical curvature and depth patterns in the developing brain. Meeting IEEE ISBI:422425.

Padilla N, Alexandrou G, Blennow M, Lagercrantz H, Aden U. 2014. Brain Growth Gains and Losses in Extremely Preterm Infants at Term. Cereb Cortex.

Rajagopalan V, Scott J, Habas PA, Kim K, Corbett-Detig J, Rousseau F, Barkovich AJ, Glenn OA, Studholme C. 2011. Local tissue growth patterns underlying normal fetal human brain gyrification quantified in utero. J Neurosci 31(8):2878-87.

Raznahan A, Greenstein D, Lee NR, Clasen LS, Giedd JN. 2012. Prenatal growth in humans and postnatal brain maturation into late adolescence. Proc Natl Acad Sci U S A 109(28):11366-71.

Raznahan A, Lee Y, Stidd R, Long R, Greenstein D, Clasen L, Addington A, Gogtay N, Rapoport JL, Giedd JN. 2010. Longitudinally mapping the influence of sex and androgen signaling on the dynamics of human cortical maturation in adolescence. Proc Natl Acad Sci U S A 107(39):16988-93.

Raznahan A, Lerch JP, Lee N, Greenstein D, Wallace GL, Stockman M, Clasen L, Shaw PW, Giedd JN. 2011 a. Patterns of coordinated anatomical change in human cortical development: a longitudinal neuroimaging study of maturational coupling. Neuron 72(5):873-84.

Raznahan A, Shaw P, Lalonde F, Stockman M, Wallace GL, Greenstein D, Clasen L, Gogtay N, Giedd JN. 2011 b. How does your cortex grow? J Neurosci 31(19):7174-7.

Regis J, Mangin JF, Ochiai T, Frouin V, Riviere D, Cachia A, Tamura M, Samson Y. 2005. "Sulcal root" generic model: a hypothesis to overcome the variability of the human cortex folding patterns. Neurol Med Chir (Tokyo) 45(1):1-17.

Ruoss K, Lovblad K, Schroth G, Moessinger AC, Fusch C. 2001. Brain development (sulci and gyri) as assessed by early postnatal MR imaging in preterm and term newborn infants. Neuropediatrics 32(2):69-74.

Scott JA, Habas PA, Kim K, Rajagopalan V, Hamzelou KS, Corbett-Detig JM, Barkovich AJ, Glenn OA, Studholme C. 2011. Growth trajectories of the human fetal brain tissues estimated from 3D reconstructed in utero MRI. Int J Dev Neurosci 29(5):529-36.

Shaw P, Eckstrand K, Sharp W, Blumenthal J, Lerch JP, Greenstein D, Clasen L, Evans A, Giedd J, Rapoport JL. 2007. Attention-deficit/hyperactivity disorder is characterized by a delay in cortical maturation. Proc Natl Acad Sci U S A 104(49):19649-54.

Shaw P, Greenstein D, Lerch J, Clasen L, Lenroot R, Gogtay N, Evans A, Rapoport J, Giedd J. 2006. Intellectual ability and cortical development in children and adolescents. Nature 440(7084):676-9.

Shaw P, Kabani NJ, Lerch JP, Eckstrand K, Lenroot R, Gogtay N, Greenstein D, Clasen L, Evans A, Rapoport JL and others. 2008. Neurodevelopmental trajectories of the human cerebral cortex. J Neurosci 28(14):358694.

Sowell ER, Peterson BS, Kan E, Woods RP, Yoshii J, Bansal R, Xu D, Zhu H, Thompson PM, Toga AW. 2007. Sex differences in cortical thickness mapped in 176 healthy individuals between 7 and 87 years of age. Cereb Cortex 17(7):1550-60.

Sowell ER, Thompson PM, Leonard CM, Welcome SE, Kan E, Toga AW. 2004. Longitudinal mapping of cortical thickness and brain growth in normal children. J Neurosci 24(38):8223-31. 
Sowell ER, Thompson PM, Rex D, Kornsand D, Tessner KD, Jernigan TL, Toga AW. 2002. Mapping sulcal pattern asymmetry and local cortical surface gray matter distribution in vivo: maturation in perisylvian cortices. Cereb Cortex 12(1):17-26.

Sun T, Patoine C, Abu-Khalil A, Visvader J, Sum E, Cherry TJ, Orkin SH, Geschwind DH, Walsh CA. 2005. Early asymmetry of gene transcription in embryonic human left and right cerebral cortex. Science 308(5729):1794-8.

Thompson PM, Cannon TD, Narr KL, van Erp T, Poutanen VP, Huttunen M, Lonnqvist J, StandertskjoldNordenstam CG, Kaprio J, Khaledy M and others. 2001. Genetic influences on brain structure. Nat Neurosci 4(12):1253-8.

Toro R, Burnod Y. 2005. A morphogenetic model for the development of cortical convolutions. Cereb Cortex 15(12):1900-13.

Travis KE, Curran MM, Torres C, Leonard MK, Brown TT, Dale AM, Elman JL, Halgren E. 2013. Age-related Changes in Tissue Signal Properties Within Cortical Areas Important for Word Understanding in 12- to 19-Month-Old Infants. Cereb Cortex.

Van Essen DC. 1997. A tension-based theory of morphogenesis and compact wiring in the central nervous system. Nature 385(6614):313-8.

van Soelen IL, Brouwer RM, van Baal GC, Schnack HG, Peper JS, Collins DL, Evans AC, Kahn RS, Boomsma DI, Hulshoff Pol HE. 2012. Genetic influences on thinning of the cerebral cortex during development. Neuroimage 59(4):3871-80.

Wallace GL, Eric Schmitt J, Lenroot R, Viding E, Ordaz S, Rosenthal MA, Molloy EA, Clasen LS, Kendler KS, Neale MC and others. 2006. A pediatric twin study of brain morphometry. J Child Psychol Psychiatry 47(10):987-93.

Westlye LT, Walhovd KB, Dale AM, Bjornerud A, Due-Tonnessen P, Engvig A, Grydeland H, Tamnes CK, Ostby Y, Fjell AM. 2010. Differentiating maturational and aging-related changes of the cerebral cortex by use of thickness and signal intensity. Neuroimage 52(1):172-85.

White T, Andreasen NC, Nopoulos P. 2002. Brain volumes and surface morphology in monozygotic twins. Cereb Cortex 12(5):486-93.

Wierenga LM, Langen M, Oranje B, Durston S. 2013. Unique developmental trajectories of cortical thickness and surface area. Neuroimage.

Wu M, Lu LH, Lowes A, Yang S, Passarotti AM, Zhou XJ, Pavuluri MN. 2013. Development of superficial white matter and its structural interplay with cortical gray matter in children and adolescents. Hum Brain Mapp.

Xue H, Srinivasan L, Jiang S, Rutherford M, Edwards AD, Rueckert D, Hajnal JV. 2007. Automatic segmentation and reconstruction of the cortex from neonatal MRI. Neuroimage 38(3):461-77. 